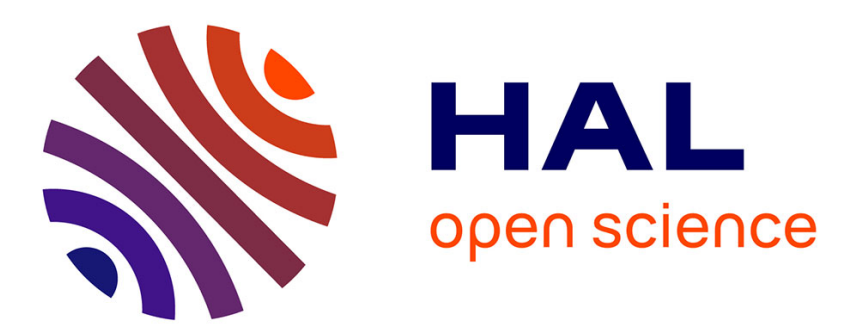

\title{
Reactivity of Acetanilides in the Alkaline Hydrolysis Reaction: Theory vs. Experiment
}

Diana Cheshmedzhieva, Sonia Ilieva, Boriana Hadjieva, Tsvetelina Trayanova, Boris Galabov

\section{- To cite this version:}

Diana Cheshmedzhieva, Sonia Ilieva, Boriana Hadjieva, Tsvetelina Trayanova, Boris Galabov. Reactivity of Acetanilides in the Alkaline Hydrolysis Reaction: Theory vs. Experiment. Molecular Physics, 2009, 107 (08-12), pp.1187-1192. 10.1080/00268970902799890 . hal-00513263

\section{HAL Id: hal-00513263 \\ https://hal.science/hal-00513263}

Submitted on 1 Sep 2010

HAL is a multi-disciplinary open access archive for the deposit and dissemination of scientific research documents, whether they are published or not. The documents may come from teaching and research institutions in France or abroad, or from public or private research centers.
L'archive ouverte pluridisciplinaire HAL, est destinée au dépôt et à la diffusion de documents scientifiques de niveau recherche, publiés ou non, émanant des établissements d'enseignement et de recherche français ou étrangers, des laboratoires publics ou privés. 


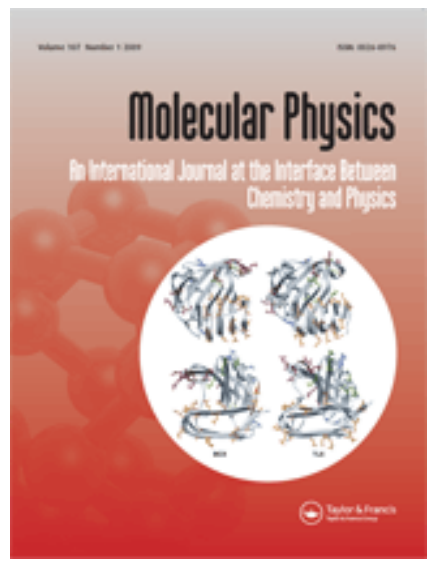

\section{Reactivity of Acetanilides in the Alkaline Hydrolysis Reaction: \\ Theory vs. Experiment}

\begin{tabular}{|r|l|}
\hline Journal: & Molecular Physics \\
\hline Manuscript ID: & TMPH-2008-0306.R1 \\
\hline Manuscript Type: & Special Issue Paper - Fritz Schaefer \\
\hline Author: & 1 Submitted by the \\
\hline Complete List of Authors: & $\begin{array}{l}\text { Cheshmedzhieva, Diana; University of Sofia, Department of } \\
\text { Chemistry } \\
\text { Ilieva, Sonia; University of Sofia, Department of Chemistry } \\
\text { Hadjieva, Boriana; University of Sofia, Department of Chemistry } \\
\text { Trayanova, Tsvetelina; University of Sofia, Department of } \\
\text { Chemistry } \\
\text { Galabov, Boris; University of Sofia, Department of Chemistry }\end{array}$ \\
\hline $\begin{array}{l}\text { Keywords: } \\
\text { alkaline hydrolysis, amides, anilides, kinetics, reactivity indices }\end{array}$ \\
\hline $\begin{array}{l}\text { Note: The following files were submitted by the author for peer review, but cannot be converted } \\
\text { to PDF. You must view these files (e.g. movies) online. }\end{array}$ \\
\hline \begin{tabular}{l} 
Supp-Inf2.doc \\
\hline
\end{tabular}
\end{tabular}

\section{今 ScholarONE Manuscript Central}




\title{
Reactivity of Acetanilides in the Alkaline Hydrolysis Reaction: Theory vs. Experiment
}

\author{
Diana Cheshmedzhieva, Sonia Ilieva, Boriana Hadjieva, Tsvetelina Trayanova, \\ Boris Galabov**1 \\ Department of Chemistry, University of Sofia, 1164 Sofia, Bulgaria \\ Dedicated to Prof. Henry F. Schaefer III, on the occasion of his 65 th anniversary
}

\begin{abstract}
The rate constants (at $25{ }^{0} \mathrm{C}$ ) for the alkaline hydrolysis of a series of seven acetanilide derivatives were experimentally determined. The series included the parent compound of acetanilide and the following para substituents: $\mathrm{CH}_{3}, \mathrm{OCH}_{3}, \mathrm{NH}_{2}, \mathrm{CHO}$, $\mathrm{COCH}_{3}, \mathrm{NO}_{2}$. The obtained kinetic data were then correlated with the following theoretically estimated reactivity indices: Mulliken and NBO atomic charges, the Parr electrophilicity index $(\omega)$, and the electrostatic potential at the carbon and nitrogen atoms of the reaction center $\left(V_{C}, V_{N}\right)$. A very good correlation between the logarithm of the rate constant, ln $\mathrm{k}$, and $\omega$ values was established. Excellent correlations between $\mathrm{V}_{\mathrm{C}}$ and $\mathrm{V}_{\mathrm{N}}$ with $\mathrm{ln} \mathrm{k}$ were found. The data obtained show that the model-independent electrostatic potential at the nuclei (EPN) provides a reliable quantitative approach in describing the reactivity of organic compounds.
\end{abstract}

Keywords: alkaline hydrolysis, amides, anilides, kinetics, reactivity indices

\section{Introduction}

The chemistry of organic reactions requires knowledge on the mechanism of the processes, the energy profile, the solvent influence, the potential role of catalysts, as well as the factors governing reactivity. Such data are usually obtained from kinetic and

\footnotetext{
${ }^{1}$ Boris Galabov

email:galabov@chem.uni-sofia.bg
} 
spectroscopic studies and, in last times, from theoretical computations. The quantitative characterization of the reactivity of organic compounds in various chemical interactions is, therefore, of key importance. It emphasizes the conceptual link between properties of reactants and their behavior in chemical reactions and supports the notion of organic chemistry as a fully quantitative science. Since the pioneering works of Hammett [1,2] the interpretation of organic reactivities has been in the focus of numerous studies. Quantum chemistry has open new perspectives in elucidating the factors governing chemical reactivity [3-23]. The introduction of reactivity indices, defined in the framework of density functional theory, has contributed to significant advances in the field [6-8, 10-16]. In spite of the impressive progress, achieving a quantitative accord between theoretical predictions and experimental kinetic data is still a challenging task. It is, therefore, paramount to characterize chemical reactivity by analyzing the agreement between theory and experiment.

We explore in the present study the application of several alternative theoretically estimated indices, which characterize the reactivity of ring-substituted acetanilides in the alkaline hydrolysis reaction. In a previous computational study [21] we evaluated several electronic structure parameters and tested their ability to predict the theoretically determined energy changes accompanying the same process. The quantities tested included two types of atomic charges, the electrophylicity index $(\omega)$ of Parr, Szentpály and Liu [12] as well as the electrostatic potential at nuclei (EPN) [24, 25]. In the present work we determined experimentally the rate constants for the alkaline hydrolysis of acetanilide and six para substituted derivatives. The experimental kinetic data were rationalized using the reactivity descriptors determined in our previous study [21].

The reaction and the compounds studied are shown in Scheme I.

Scheme I

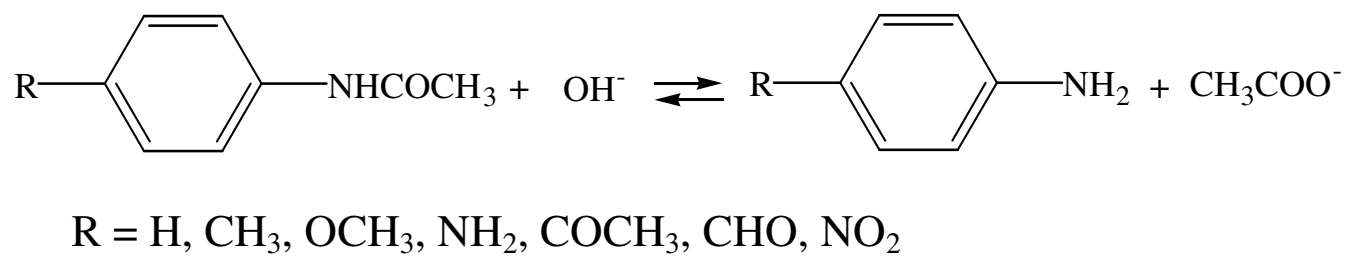


The series includes a balanced number of derivatives containing electron donating and electron withdrawing substituents. The para-substitution is preferred in order to minimize possible steric influences on the reaction rates.

The amide hydrolysis has been the subject of numerous experimental [26-36] and theoretical studies [37-57] because it is regarded as a model process for the cleavage of peptide bonds [58]. In a recent combined kinetic and computational study [57] we showed that the rate of the alkaline hydrolysis of three secondary amides - Nmethylbenzamide, $\mathrm{N}$-methylacetamide and acetanilide - is governed by the second stage of the reaction. This stage involves the breakdown of the initially formed tetrahedral intermediate to products. The computational and kinetic results provided a detailed picture of the variations of the free energy barriers for the reactions of the three amides studied.

In the present work we examine how different electronic structure parameters obtained from quantum mechanical computations predict the relative rates of the alkaline hydrolysis of substituted acetanilides. On the experimental side rate constants for the alkaline hydrolysis of a series of acetanilides at $25^{\circ} \mathrm{C}$ were experimentally determined.

\section{Computational Results and Kinetic Experiments}

The rates of hydrolysis of the studied acetanilides were measured spectrophotometrically. The change in absorbance due to the reactant amides and the products, were followed on a Unicam UV500 spectrometer at the $\lambda_{\max }$ for the respective final products (anilines) or initial acetanilides. The hydroxide ion concentration was 0.9 $\mathrm{M}$ and the ionic strength was maintained constant at $0.9 \mathrm{M}(\mathrm{NaCl})$. The initial concentrations of amides were about $1.10^{-4} \mathrm{M}$. The hydroxide concentration was in a large excess, so the reactions exhibited pseudo-first-order kinetics. Kinetic data were generated to estimate the rate constants, $k_{o b s}$, by plotting $\ln \left(A_{\infty}-A_{t}\right)$ vs. time, where $A_{\infty}$ is the absorbance of the respective aniline at time $t=\infty$ or the pure aryl amine. The slope of the line yielded $\mathrm{k}_{\mathrm{obs}}$. Alternatively, in the cases where changes in the concentration of initial reactants were followed the relation $\ln \left(\mathrm{A} / \mathrm{A}_{0}\right)$ vs. time was applied. The kinetic measurements were carried out at $25 \pm 0.1^{\circ} \mathrm{C}$. Temperatures were kept constant by a 
thermostat. The reactions were followed to over $80 \%$ transformation of the initial amides. In every case $k_{o b s}$ is the average of three independent measurements. The linear dependence of $\ln \left(\mathrm{A}_{\infty}-\mathrm{A}_{\mathrm{t}}\right)$ or $\ln \left(\mathrm{A} / \mathrm{A}_{0}\right)$ vs. time showed that the reactions had obeyed pseudo-first-order kinetics. Dividing the values by the concentration of the hydroxide ions normalized the obtained pseudo-first-order constants. Bender and Thomas [26] have shown that the alkaline hydrolysis of acetanilides follows second order kinetics. Details of the kinetic experiments are provided in the Supporting Information.

The acetanilide and two of the $p$-substituted acetanilides $\left(\mathrm{R}=\mathrm{H}, \mathrm{NH}_{2}, \mathrm{NO}_{2}\right)$ were synthesized by known methods via amidation of acetic acid or acetic anhydride with the respective $p$-substituted anilines $[59,60]$. The rest of the $p$-substituted acetanilides from the studied series are commercial products.

The following theoretical quantities employed as reactivity indices were applied in rationalizing the rates of alkaline hydrolysis:

(i) Mulliken atomic charges [61] at the carbonyl carbon atom, which is the reaction center for the attack by the hydroxide ion.

(ii) Natural Bond Orbital (NBO) atomic charges [62, 63]. These charges have proved a superior tool for population analysis.

(iii) The electrophilicity index ( $\omega)$ of Parr, Szentpály and Liu [12] defined by the relationship: $\omega=\mu^{2} / 2 \eta$ was considered as well. $\mu$ is the electronic chemical potential and $\eta$ is the total hardness.

(iv) The electrostatic potential at nuclei was also applied. This quantity is defined by Eqn. 1, where the singular term $\mathbf{R}_{\mathrm{A}}=\mathbf{R}_{\mathrm{Y}}$ has been excluded [24,25]:

$$
V_{Y} \equiv V\left(R_{Y}\right)=\sum_{A \neq Y} \frac{Z_{A}}{\left|R_{Y}-R_{A}\right|}-\int \frac{\rho\left(r^{\prime}\right)}{\left|R_{Y}-r^{\prime}\right|} d r^{\prime}
$$

In this relation, $Z_{\mathrm{A}}$ is the charge on nucleus $\mathrm{A}$ with radius vector $R_{\mathrm{A}}, \rho(r)$ is the electronic density function of the respective molecule, and $r^{\prime}$ is a dummy integration variable. Equation (1) is written in atomic units and contains a summation over all atomic nuclei, treated as positive point charges, as well as integration over the continuous distribution of the electronic charge. The EPN index was defined and introduced by 
Wilson [25] in the distant 1962. However, it was first applied as a reactivity index for organic compounds much later in the works of Galabov et al. [20-22].

The values of the theoretical indices tested, including Mulliken and NBO atomic charges, $\mathrm{V}_{\mathrm{C}}$ and $\omega$, are taken from our previous work on the reactivity of acetanilides [21]. These quantities were determined by computations at the B3LYP/6-31+G(d,p) level of theory.

\section{Results and Discussion}

As already emphasized, the principal aim of this study was to analyze the correlations between theoretically evaluated reactivity indices for the studied series of acetanilides and the experimentally determined rate constants for the reaction of alkaline hydrolysis. The obtained rate constants (at $25{ }^{0} \mathrm{C}$ ) for the hydrolysis of the seven acetanilides are presented in Table 1. It should be mentioned that kinetic data for the alkaline hydrolysis of acetanilide as well as the respective $\mathrm{p}-\mathrm{CH}_{3}, \mathrm{p}-\mathrm{OCH}_{3}$, and $\mathrm{p}-\mathrm{Cl}$ derivatives were previously reported by Bender at al. [26]. In another study Sorci and Macalady [36] provided experimental kinetic results for the alkaline hydrolysis of para substituted acetanilides. The series of seven acetanilides of these authors included several different substituents compared to the series considered in the present research.

The experimentally determined in the present study rate constants were juxtaposed to theoretical reactivity indices, which were determined in our previous computational study on this reaction [21]. The respective values for these electronic parameters are given in Table 2. Table 2 contains also the usual Hammett constants for the substituents. In the bottom row of the table are shown the linear regression correlation coefficients ( $r$ ) for the dependences between the $\mathrm{ln} \mathrm{k}$ values and the respective reactivity parameters. It is seen that the Mulliken charges do not correlate linearly with the $\ln \mathbf{k}$ values. A better correlation, though far from satisfactory, is obtained when the NBO charges on the carbonyl carbon are applied. This dependence is illustrated in Figure 1. The plot between $\omega$ and $\ln k$ is presented in Figure 2. It is seen that for this reaction the global electrophilicity index provides very good predictions for the relative reaction rates. The plot between the electrostatic potential at the carbonyl carbon atom $\left(\mathrm{V}_{\mathrm{C}}\right)$ and $\ln \mathrm{k}$ is shown in Figure 3. This linear plot is characterized by the highest correlation coefficient $(\mathrm{r}=$ 
0.990). Surprisingly, the standard Hammett sigma constants do not provide satisfactory results for this reaction.

The variations of the electrostatic potential values as well as the NBO charges at the electrophilic center reflect clearly the influence of polar groups at the para position in the aromatic ring. The increased partial positive charge at the carbonyl carbon under the influence of electron withdrawing substituents favors the interaction between the two reactants. Inversely, electron donating substituents, such as $\mathrm{CH}_{3}, \mathrm{OCH}_{3}$ and $\mathrm{NH}_{2}$, lead to increased electron density at the site of the electrophilic center, thus hampering its interaction with the electronegative hydroxide ion.

As we have recently discussed [57], the rate-limiting stage of the reaction studied is associated with the second transition state (TS2). This stage involves simultaneous breaking of the amide $\mathrm{C}-\mathrm{N}$ bond and the transfer of a proton to the emerging amine anion. The significantly increased negative charge at the amide nitrogen in TS2 reflects in the lower values of $V_{N}$ in TS2 compared to reactants seen in Table 2. The nascent negative charge at the nitrogen atom can be stabilized by electron delocalisation toward the aromatic ring. This process is strongly favoured by electron withdrawing substituents, such as $\mathrm{CHO}, \mathrm{COCH}_{3}$ and $\mathrm{NO}_{2}$ groups. It is, therefore, not surprising that acetanilides containing these substituents react much faster than the unsubstituted acetanilide or derivatives with electron donating groups. The linear dependences between rate constants and the electrostatic potential at the nitrogen atom in both reactants and transition state are characterized by high correlation coefficients. The plot between $\ln \mathrm{k}$ and $\mathrm{V}_{\mathrm{N}}$ in reactants is illustrated in Fig. 4.

The excellent correlations between the electrostatic potential at nuclei and $\mathrm{ln} \mathrm{k}$ values are not surprising. We have shown in a series of papers [20-22] that EPN provides superb quantitative predictions of reactivities for a number of charge-controlled processes. This index has two characteristics that are behind its successful applications in describing the chemical reactivity: (1) It is a local index, characterizing the reactivity of atoms in particular reaction center in molecules; (2) No further assumptions or approximations with respect to the wave function considered are introduced. Thus the electrostatic potential at nuclei reflects accurately fine variations in the electron density at particular atomic sites 
caused by structural changes. Further studies in other laboratories [64-71] have emphasized the usefulness at this proposed reactivity index.

It is especially important that $\mathrm{V}_{\mathrm{C}}$ and $\mathrm{V}_{\mathrm{N}}$ work so well with respect to both theoretically estimated barrier heights and in predicting quantitatively the experimental reaction rates. In a recent experimental and computational study within a series of phenyl acetates [20] the electrostatic potential at nuclei of the carbonyl reaction center provided spectacular quantitative prediction of the rate constants. The data obtained in this study further emphasize the wider applicability of this quantity. In a more general perspective, the present results show also that current theoretical computations provide a basis for a future fully quantitative description of the properties of organic compounds.

\section{Summary}

The kinetic constants $\left(\right.$ at $25{ }^{0} \mathrm{C}$ ) for the alkaline hydrolysis of a series of seven para-substituted acetanilides were experimentally determined. The kinetic data were then correlated with several reactivity indices estimated theoretically. The theoretical quantities included Mulliken and NBO atomic charges, the Parr electrophilicity index $(\omega)$, and the electrostatic potential at the carbon and nitrogen atoms of the reaction center $\left(\mathrm{V}_{\mathrm{C}}, \mathrm{V}_{\mathrm{N}}\right)$. Very good linear dependence between $\ln \mathrm{k}$ and $\omega$ values was established. This result emphasizes the usefulness of $\omega$ in discussing the chemical reactivity of organic system. Excellent linear correlations between $V_{C}$ and $V_{N}$ with $\ln k$ were found. The data obtained show that the model-independent EPN values provide reliable quantitative approach in describing the reactivity of organic compounds studied up to now.

\section{Acknowledgement}

Professor Wesley D. Allen is thanked for comments on the manuscript. This research was supported by the National Science Fund in Bulgaria, grant VU X-04/05. 


\section{References:}

[1] L.P. Hammett, J. Am. Chem. Soc. 59, 96, (1937).

[2] L.P. Hammett, Trans. Faraday Soc. 34, 156, (1938).

[3] K. Fukui, Theory of Orientation and Stereoselection. Reactivity and Structure Concepts in Organic Chemistry; Vol. 2 (Springer: Berlin, 1975).

[4] G. Klopman, Ed., Chemical Reactivity and Reaction Paths, (Wiley: New York, 1974).

[5] F.A. Carey R. J. Sanders, Advanced Organic Chemistry (Springer, New York, 1990).

[6] R.G. Parr, W. Yang, Density Functional Theory of Atoms and Molecules (Oxford University Press, New York, 1989).

[7] K.D. Sen, C.K. Jorgersen, editors, Electronegativity, Structure and Bonding (Springer: Berlin, 1993).

[8] R.G. Pearson, Chemical Hardness: Applications from Molecules to Solids (WileyVCH, Weinheim, Germany, 1997).

[9] J.S. Murray, K.D. Sen, Molecular Electrostatic Potentials. Concepts and Applications (Elsevier, Amsterdam, 1996).

[10] K.D. Sen, Editors, Reviews of Modern Quantum Chemistry; 2 Vols. (World Scientific, Singapore, 2002).

[11] A. Toro-Labbe, Theoretical Aspects of Chemical Reactivity (Elsevier: Amsterdam, 2006).

[12] R.G. Parr, L.V. Szentpály, S. Liu, J. Am. Chem. Soc. 121,1922 (1999).

[13] Y. Li, N. S. Evans, J. Am. Chem. Soc. 117, 7756 (1995).

[14] P.K. Chattaraj, U. Sarkar, D.R. Roy, Chem. Rev. 106, 2065 (2006); P.K. Chattaraj, D.R. Roy, ibid. 107 (2007) DOI: 10.1021/cr078014b.

[15] H. Chermette, J. Comput. Chem. 20, 129 (1999). 
[16] P. Geerlings, F. De Proft, W. Langenaeker, Chem. Rev. 103, 1793 (2003).

[17] J.S. Murray, P. Politzer, Chem. Phys. Lett. 152, 364 (1988).

[18] J.S. Murray, P. Lans, T. Brinck, P. Politzer, J. Phys. Chem. 95, 844 (1991).

[19] P. Politzer, J.S. Murray, Int. J. Quant. Chem. 88, 19 (2002).

[20] P. Bobadova-Parvanova, B. Galabov, J. Phys. Chem. A 102, 1815 (1998); B. Galabov, P. Bobadova-Parvanova, ibid. 103, 6793 (1999); V. Dimitrova, S. Ilieva, B. Galabov, ibid.106, 11801 (2002); B. Galabov, S. Ilieva, B. Hadjieva, Y. Atanasov, H. F. Schaefer, ibid. 112, 6700 (2008).

[21] B. Galabov, D. Cheshmedzhieva, S. Ilieva, B. Hadjieva, J. Phys. Chem. A, 108, 11457 (2004).

[22] B. Galabov, V. Nikolova, J.J. Wilke, H.F. Schaefer, W.D. Allen, J. Am. Chem. Soc. 130, 9887 (2008).

[23] C.H. Suresh, S.R. Gadre J. Org. Chem. 62, 2625 (1997); J. Am. Chem. Soc. 120, 7049 (1998); J. Phys. Chem. A 111, 710 (2007).

[24] P. Politzer, in Chemical Applications of Atomic and Molecular Electrostatic Potentials; Edited by P. Politzer and D.G. Truhlar (Plenum Press: New York, 1981) p. 7.

[25] E. B. Wilson Jr., J. Chem. Phys. 36, 2232 (1962).

[26] M.L. Bender, R.J. Thomas, J. Am. Chem. Soc. 8, 4183 (1961).

[27] M.L. Bender, R.D. Ginger, K.C. Kemp, J. Am. Chem. Soc. 76, 3350 (1954); P.M. Mader, ibid. 87, 3191 (1965); M.L. Bender, R.D. Ginger, J.P. Unik, ibid. 80, 1044 (1958); R.M. Polack, M.L. Bender, ibid. 92, 7190 (1970); S.S. Biechler, R.W. Taft, ibid. 79, 4927 (1957).

[28] M.L. Bender, Chem. Rev. 60, 53 (1960).

[29] R.L. Schowen, G.W. Zuorick, J. Am. Chem. Soc. 88, 1223 (1966); R.L. Schowen, H. Jayaraman, L. Kershner, ibid. 88, 3373 (1966); R.L. Schowen, H. Jayaraman, L. Kershner, G.W. Zuorick, ibid. 88, 4008 (1966); L.D. Kershner, R.L. Schowen, ibid. 93, 2014 (1971); I.H. Williams, G.M. Maggiora, R.L. Schowen, ibid. 102, 7831 (1980). 
[30] J.K. Young, S. Pazhanisamy, R.L. Schowen, J. Org. Chem. 49, 4148 (1984).

[31] S.O. Eriksson, Acta Chem. Scand. 20, 1892 (1966); S.O. Eriksson, ibid. 22, 892 (1968).

[32] H. Slebocka-Tilk, A.J. Bennet, H.J. Hogg, R.S. Brown, J. Am. Chem. Soc. 113, 1288 (1991); H. Slebocka-Tilk, A. Neverov, R.S. Brown, ibid. 125, 1851 (2003); H. Slebocka-Tilk, A.J. Bennet, J.W. Keillor, R.S. Brown, J.P. Gutrie, A. Jodhan, ibid. 112, 8507 (1990).

[33] R.S. Brown, A.J. Bennet, H. Slebocka-Tilk, Acc. Chem. Res. 25, 481 (1992).

[34] V. Gani, P. Viout, Tetrahedron 32, 1669 (1976).

[35] N.J. Buurma, M.J. Blandamer, J.B.F.N. Engberts, J. Phys. Org. Chem. 16, 438 (2003).

[36] J.J. Sorci, D.L. Macalady, J. Agric. Food Chem, 41, 1760 (1993).

[37] S. Scheiner, W.N. Lipscomb, D.A. Kleier, J. Am. Chem. Soc. 98, 4770 (1976); J.D. Madura, W.L. Jorgensen, ibid. 108, 2517 (1986); J.S. Francisco, I.H. Williams, ibid. 115, 3746 (1993).

[38] G.M. Maggiora, I.H. Williams, J. Mol. Struct. (THEOCHEM) 88, 23 (1982).

[39] O.N. Ventura, E.L. Coitino, A. Lledos, J. Bertran, J. Comp. Chem. 13, 1037 (1992).

[40] K. Hori, A. Kamimura, K. Ando, M. Mizumura, Y. Ihara, Tetrahedron 53, 4317 (1988).

[41] S. Antonczak, M.F. Ruiz-Lopez, J.L. Rivail, J. Am. Chem. Soc. 116, 3912 (1994); S. Antonczak, G. Monard, M.F. Ruiz-Lopez, J.L. Rivail, ibid. 120, 8825 (1998); J. Pitarch, M. F. Ruiz-Lopez, E. Silla, J. L. Pascual-Ahuir, I. Tunon, ibid. 120, 2146 (1998).

[42] S. Chalmet, W. Harb, M. F. Ruiz-López, J. Phys. Chem. A. 105, 11574 (2001).

[43] S.J. Weiner, U.C. Singh, P.A. Kollman, J. Am. Chem. Soc. 107, 2219 (1985); A. E. Howard, P. A. Kollman, ibid. 110, 7195 (1988); D. Bakowies, P. A. Kollman, ibid. 121, 5712 (1999). 
[44] M. Strajbl, J. Florian, A. Warshel, J. Am. Chem. Soc. 122, 5354 (2000).

[45] D. Zahn, Chem Phys Lett. 383, 134 (2004); Chem Phys 300, 79 (2004); J. Phys. Chem. B. 107, 12303 (2003); Eur. J. Org. Chem. 2004, 4020.

[46] Y. Xiong, C. Zhan, J. Phys. Chem. A 110, 12644 (2006).

[47] J. Pitarch, M. F. Ruiz-Lopez, J. L. Pascual-Ahuir, E. Silla, I. Tunon, J. Phys. Chem. B 101, 3581 (1997).

[48] J. Pitarch, J.L. Pascual-Ahuir, E. Silla, I. Tunon, M.F. Ruiz-Lopez, C. Millot, J. Bertran, Theor. Chem. Acc. 101, 336 (1999).

[49] L. Gorb, A. Asensio, I. Tuñón, M.F. Ruiz-López, Chem Eur. J. 11, 6743 (2005).

[50] a) X. Lopez, J.I. Mujika, G.M. Blackburn, M. Karplus, J. Phys. Chem. A 107, 2304 (2003).

[51] J.I. Mujika, J.M. Mercero, X. Lopez, J. Am. Chem. Soc. 127, 4445 (2005).

[52] D. Cheshmedzhieva, S. Ilieva, B. Galabov, J. Mol. Struct. (THEOCHEM) 681, 105 (2004).

[53] J.R. Pliego, Jr., J.M. Riveros, Chem Eur. J. 8, 1945 (2002).

[54] J R. Pliego Jr., Chem. Phys. 306, 273 (2004).

[55] J. Blumberger, M. Klein, Chem Phys Lett. 422, 210 (2006).

[56] M. Cascella, S. Raugei, P. Carloni, J. Phys. Chem. B 108, 369 (2004).

[57] D. Cheshmedzhieva, S. Ilieva, B. Hadjieva, B. Galabov, J. Phys. Org. Chem. (2008), in press.

[58] R.S. Brown, in The Amide Linkage: Selected Structural Aspects in Chemistry, Biochemistry, and Materials Science, edited by C. M. Breneman, A. Greenberg, J. F. Liebman (Wiley Interscience, New York, 1999) p. 85.

[59] A. Merril, J. Am. Chem. Soc. 39, 1545 (1917).

[60] J. Rosevear, J.F.K. Wilshir, Aust. J. Chem. 38, 723 (1985).

[61] R.S. Mulliken, J. Chem. Phys. 23, 1833 (1955). 
[62] A.E. Reed, R.B. Weinstock, F. Weinhold, J. Chem. Phys. 83, 735 (1985).

[63] A.E. Reed, L.A. Curtiss, F. Weinhold, Chem. Rev. 88, 899 (1988)

[64] J.M. Alia, H.G. Edwards, J. Phys. Chem. A 109, 7977 (2005); Int. J. Quantum Chem. 107, 1170 (2007).

[65] A. Karpfen, E.S. Kryachko, J. Phys. Chem. A 109, 8930 (2005).

[66] W.X. Zheng, N.B. Wong, W.K. Li, J. Phys. Chem. A 108, 11721 (2004); W.X. Zheng, N.B. Wong, A. Tian, ibid. 109, 1926 (2005).

[67] N. Sadlej-Sosnowska, J. Phys. Chem. A. 111, 11134 (2007); Polish J. Chem. 81, 1123 (2007); Chem. Phys. Lett. 447, 192 (2007).

[68] N. Sadlej-Sosnowska, K. Murlowska, J. Phys. Chem. A 112, 10017(2008).

[69] A. Cedillo, R. Contreras, M. Galvan, A. Aizman, J. Andres, V.S. Safont, J. Phys. Chem. A 111, 2442 (2007).

[70] S.B. Novakovic, B. Fraisse, G.A.Bogdanovic, A. Spasojevic-de Bire, Cryst. Growth Des. 7, 191 (2007).

[71] S.B. Novakovic, G.A. Bogdanovic, B. Fraisse, N.E. Ghermani, N. Bouhmaida, A. Spasojevic-de Bire, J. Phys. Chem. A 111, 13492 (2007).

[72] C. Hansch, A. Leo, R.W. Taft, Chem. Rev. 91, 165 (1991). 
Table 1. Experimentally determined rate constants at $25{ }^{0} \mathrm{C}$ for the alkaline hydrolysis of acetanilide and p-substituted acetanilides.

\begin{tabular}{lccc}
\hline Substituent & $\mathbf{k}_{\mathbf{0 b s}}\left[\mathbf{s}^{-\mathbf{1}}\right]$ & $\mathbf{k}^{[\mathrm{a}]}\left[\mathbf{s}^{-\mathbf{1}} \mathbf{M}^{-\mathbf{1}}\right]$ & $\mathbf{l n} \mathbf{k}$ \\
\hline $\mathbf{H}$ & $6.38 \mathrm{E}-06$ & $7.09 \mathrm{E}-06$ & -11.8564 \\
$\mathbf{C H}_{3}$ & $5.91 \mathrm{E}-06$ & $6.57 \mathrm{E}-06$ & -11.9335 \\
$\mathbf{O C H}_{\mathbf{3}}$ & $6.34 \mathrm{E}-06$ & $7.04 \mathrm{E}-06$ & -11.8633 \\
$\mathbf{N H}_{\mathbf{2}}$ & $1.95 \mathrm{E}-06$ & $2.16 \mathrm{E}-06$ & -13.0438 \\
$\mathbf{C O C H}$ & $4.61 \mathrm{E}-05$ & $5.12 \mathrm{E}-05$ & -9.8798 \\
$\mathbf{C H O}$ & $1.45 \mathrm{E}-04$ & $1.61 \mathrm{E}-04$ & -8.7343 \\
$\mathbf{N O}_{\mathbf{2}}$ & $6.17 \mathrm{E}-04$ & $6.86 \mathrm{E}-04$ & -7.2847 \\
${ }^{[\mathrm{a}]}{ }_{\mathrm{k}=\mathrm{k}_{\mathrm{obs}} /\left[\mathrm{OH}^{-}\right] .}$ & &
\end{tabular}

Table 2. Theoretical reactivity indices from B3LYP/6-31+G(d,p) computations ${ }^{[\mathrm{a}]}$ and Hammett constants for acetanilide and p-substituted derivatives.

\begin{tabular}{|c|c|c|c|c|c|c|c|c|}
\hline Substituent & $\mathbf{q}_{\mathrm{C}} \mathbf{M P A}$ & $q_{C}$ NBO & $\omega$ & $\begin{array}{l}\mathbf{V}_{\mathbf{C}}[\mathbf{a u}] \\
\text { Reactant }\end{array}$ & $\begin{array}{c}\mathbf{V}_{\mathbf{N}}[\mathbf{a u}] \\
\text { Reactant }\end{array}$ & $\begin{array}{c}\mathbf{V}_{\mathbf{N}}[\mathbf{a u}] \\
\mathrm{TS} 2\end{array}$ & $\begin{array}{l}\text { Hammett } \sigma \\
\text { constants }^{[b]}\end{array}$ & $\ln k$ \\
\hline $\mathbf{H}$ & 0.7285 & 0.6782 & 1.11 & -14.6199 & -18.2891 & -18.5326 & 0.000 & -11.8564 \\
\hline $\mathrm{CH}_{3}$ & 0.7453 & 0.6767 & 1.04 & -14.6228 & -18.2917 & -18.5377 & -0.170 & -11.9335 \\
\hline $\mathrm{OCH}_{3}$ & 0.7926 & 0.6747 & 0.94 & -14.6243 & -18.2926 & -18.5360 & -0.268 & -11.8633 \\
\hline $\mathbf{N H}_{2}$ & 0.7361 & 0.6725 & 0.87 & -14.6283 & -18.2965 & -18.5444 & -0.660 & -13.0438 \\
\hline $\mathrm{COCH}_{3}$ & 0.7958 & 0.6818 & 1.91 & -14.6089 & -18.2771 & -18.4916 & 0.502 & -9.8798 \\
\hline CHO & 0.7556 & 0.6829 & 2.10 & -14.6051 & -18.2729 & -18.4877 & 0.420 & -8.7343 \\
\hline $\mathrm{NO}_{2}$ & 0.7492 & 0.6847 & 2.86 & -14.5978 & -18.2647 & -18.4549 & 0.778 & -7.2847 \\
\hline $\begin{array}{l}\text { Correlation } \\
\text { coefficient }^{[\mathrm{c}]}\end{array}$ & 0.173 & 0.952 & 0.985 & 0.990 & 0.993 & 0.986 & 0.947 & \\
\hline
\end{tabular}

${ }^{[\mathrm{a}]}$ Values are taken from ref. 21.

[b] From ref. 74.

${ }^{[c]}$ Correlation coefficients for the linear plots between reactivity indices and $\ln \mathrm{k}$. 
Figure 1. Plot of ln k vs. carbonyl carbon NBO charges $\left(\boldsymbol{q}_{C}^{N B O}\right)$ for the alkaline hydrolysis of the series of acetanilides studied.

Figure 2. Plot of ln k vs. global electrophilicity index $(\omega)$ for the alkaline hydrolysis of the series of acetanilides studied.

Figure 3. Plot of $\ln \mathrm{k}$ vs. the electrostatic potential at carbonyl carbon atom $\left(\mathrm{V}_{\mathrm{C}}\right)$ for the alkaline hydrolysis of the series of acetanilides studied.

Figure 4. Plot of ln k vs. the electrostatic potential at the nitrogen atom $\left(\mathrm{V}_{\mathrm{N}}\right)$ for the alkaline hydrolysis of the series of acetanilides studied. 
1

2

3

4

5

6

7

8

9

10

11

12

13

14

15

16

17

18

19

20

21

22

23

24

25

26

27

28

29

30

31

32

33

34

35

36

37

38

39

40

41

42

43

44

45

46

47

48

49

50

51

52

53

54

55

56

57

58

59

60

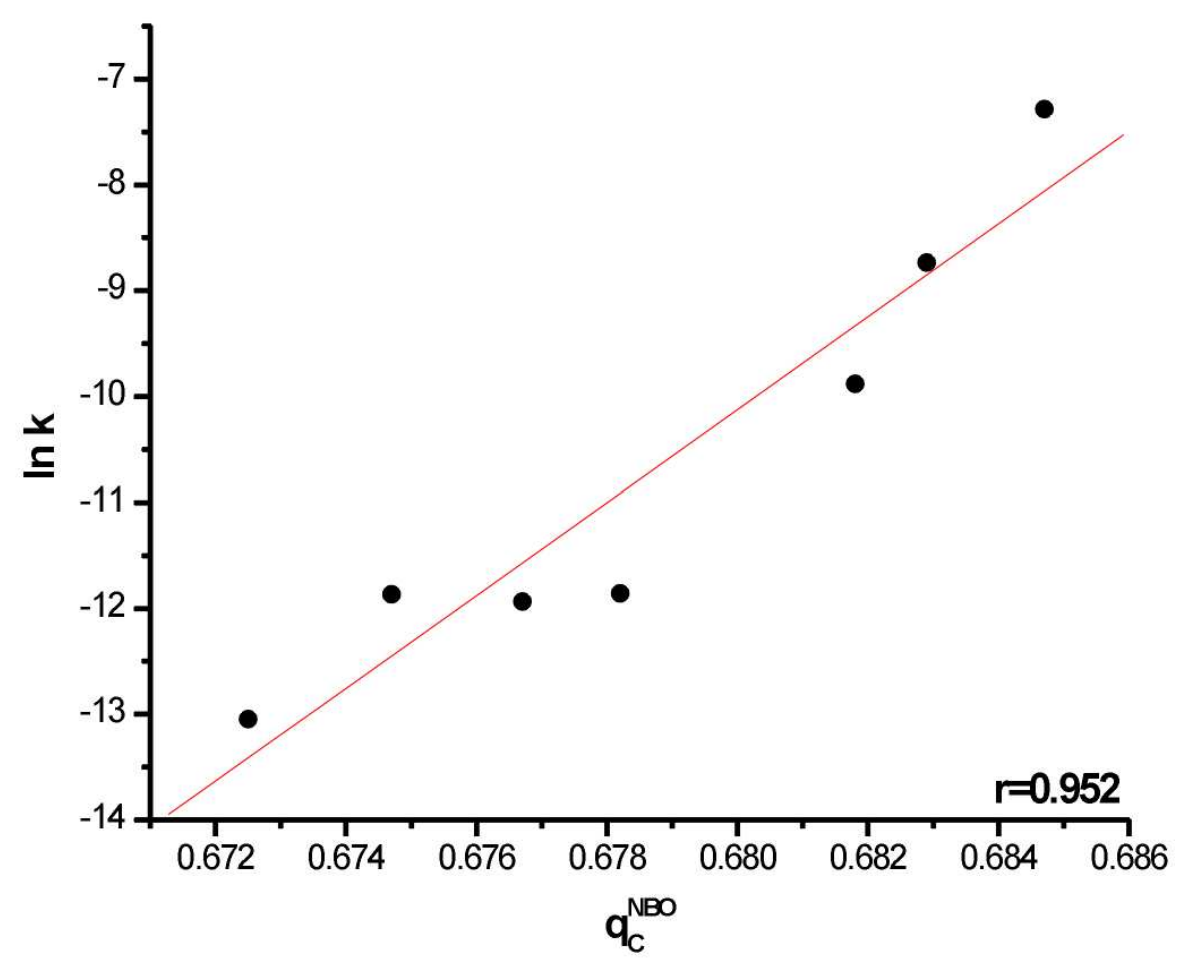

Figure 1. Plot of In k vs. carbonyl carbon NBO charges for the alkaline hydrolysis of the series of acetanilides studied. 
Figure 2. Plot of In k vs. global electrophilicity index $(\omega)$ for the alkaline hydrolysis of the series of acetanilides studied. 
Figure 3. Plot of In k vs. the electrostatic potential at carbonyl carbon atom $\left(V_{c}\right)$ for the alkaline hydrolysis of the series of acetanilides studied. 
Figure 4. Plot of In k vs. the electrostatic potential at the nitrogen atom $\left(\mathrm{V}_{\mathrm{N}}\right)$ for the alkaline hydrolysis of the series of acetanilides studied. 


\title{
Supporting information
}

\section{Reactivity of Acetanilides in the Alkaline Hydrolysis Reaction:} Theory vs. Experiment

\author{
Diana Cheshmedzhieva, Sonia Ilieva, Boriana Hadjieva, Tsvetelina Trayanova, \\ Boris Galabov* \\ Department of Chemistry, University of Sofia, 1164 Sofia, Bulgaria
}

Dedicated to Prof. Henry F. Schaefer III, on the occasion of his 65th anniversary

\section{Table of Contents}

(1) Tables S1 - S7. Summary of rate constants at $25^{\circ} \pm 0.1^{\circ} \mathrm{C}$ for the seven studied acetanilides. In all the cases $\left[\mathrm{OH}^{-}\right]=0.9 \mathrm{M}---------------------------------------------(\mathrm{S} 2$ - S3)

\footnotetext{
* Boris Galabov email: galabov@chem.uni-sofia.bg
} 
Table S1. Summary of rate constants from the three separate measurements for the alkaline hydrolysis of acetanilide at $25^{\circ} \pm 0.1^{\circ} \mathrm{C}$.

\begin{tabular}{ccc}
\hline Sample \# & $\mathrm{k}[\mathrm{s}-1]$ & $\mathrm{R}$ \\
\hline I & $6.51 \mathrm{E}-06$ & 0.9956 \\
II & $6.39 \mathrm{E}-06$ & 0.9971 \\
III & $6.26 \mathrm{E}-06$ & 0.9953 \\
\hline
\end{tabular}

Table S2. Summary of rate constants from the three separate measurements for the alkaline hydrolysis of p-methylacetanilide at $25^{\circ} \pm 0.1^{\circ} \mathrm{C}$.

\begin{tabular}{ccc}
\hline Sample \# & $\mathrm{k}[\mathrm{s}-1]$ & $\mathrm{R}$ \\
\hline I & $5.83 \mathrm{E}-06$ & 0.9965 \\
II & $6.02 \mathrm{E}-06$ & 0.9953 \\
III & $5.87 \mathrm{E}-06$ & 0.9973 \\
\hline
\end{tabular}

Table S3. Summary of rate constants from the three separate measurements for the alkaline hydrolysis of p-methoxyacetanilide at $25^{\circ} \pm 0.1^{\circ} \mathrm{C}$.

\begin{tabular}{ccc}
\hline Sample \# & $\mathrm{k}[\mathrm{s}-1]$ & $\mathrm{R}$ \\
\hline $\mathrm{I}$ & $6.38 \mathrm{E}-06$ & 0.9987 \\
II & $6.33 \mathrm{E}-06$ & 0.9987 \\
III & $6.33 \mathrm{E}-06$ & 0.9989 \\
\hline
\end{tabular}

Table S4. Summary of rate constants from the three separate measurements for the alkaline hydrolysis of $\mathrm{p}$-aminoacetanilide at $25^{\circ} \pm 0.1^{\circ} \mathrm{C}$.

\begin{tabular}{ccc}
\hline Sample \# & $\mathrm{k}$ [s-1] & $\mathrm{R}$ \\
\hline I & $1.89 \mathrm{E}-06$ & 0.9948 \\
II & $1.96 \mathrm{E}-06$ & 0.9974 \\
III & $1.99 \mathrm{E}-06$ & 0.9956 \\
\hline
\end{tabular}

Table S5. Summary of rate constants from the separate measurements for the alkaline hydrolysis of p-acetylacetanilide at $25^{\circ} \pm 0.1^{\circ} \mathrm{C}$.

\begin{tabular}{ccc}
\hline Sample \# & $\mathrm{k}$ [s-1] & $\mathrm{R}$ \\
\hline $\mathrm{I}$ & $4.49 \mathrm{E}-05$ & 0.9988 \\
$\mathrm{II}$ & $4.73 \mathrm{E}-05$ & 0.9984 \\
\hline
\end{tabular}


Table S6. Summary of rate constants from the three separate measurements for the alkaline hydrolysis of p-acetamidobenzaldehyde at $25^{\circ} \pm 0.1^{\circ} \mathrm{C}$.

\begin{tabular}{ccc}
\hline Sample \# & $\left.\mathrm{k} \mathrm{[s}^{-1}\right]$ & $\mathrm{R}$ \\
\hline I & $1.48 \mathrm{E}-04$ & 0.9937 \\
II & $1.42 \mathrm{E}-04$ & 0.9972 \\
III & $1.44 \mathrm{E}-04$ & 0.9966 \\
\hline
\end{tabular}

Table S7. Summary of rate constants from the three separate measurements for the alkaline hydrolysis of p-nitroacetanilide at $25^{\circ} \pm 0.1^{\circ} \mathrm{C}$.

\begin{tabular}{ccc}
\hline Sample \# & $\left.\mathrm{k} \mathrm{[s}^{-1}\right]$ & $\mathrm{R}$ \\
\hline I & $6.36 \mathrm{E}-04$ & 0.9996 \\
II & $6.35 \mathrm{E}-04$ & 0.9994 \\
III & $5.81 \mathrm{E}-04$ & 0.9873 \\
\hline
\end{tabular}

